\title{
moda na filosofia
}

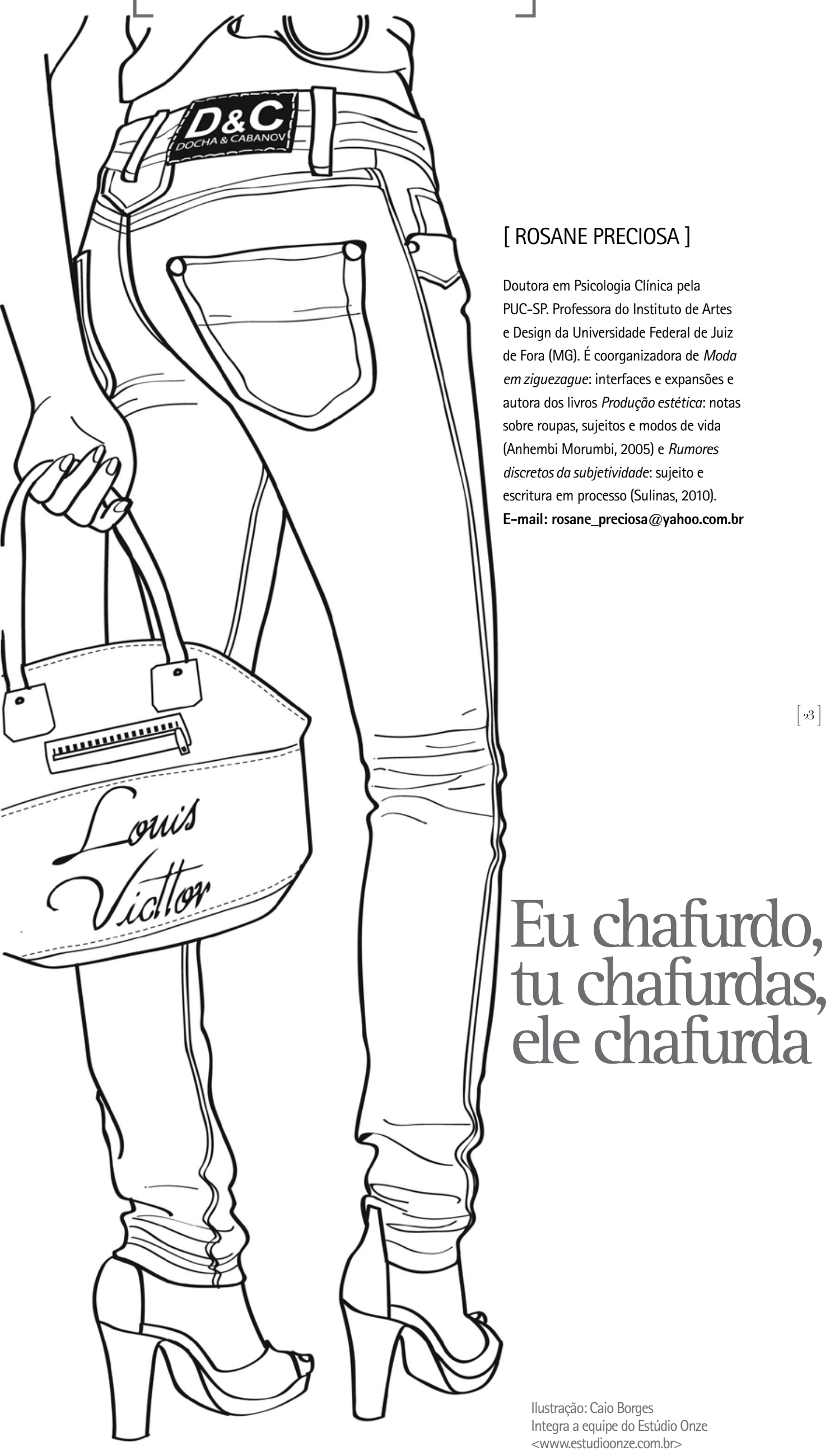




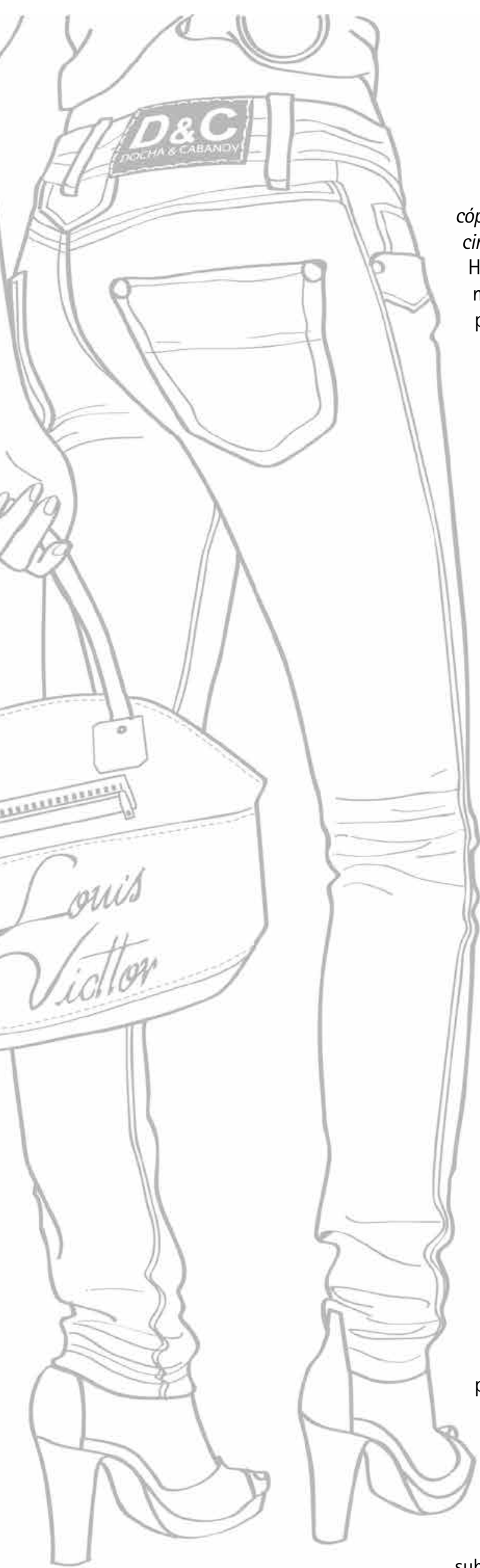

0 título da dissertação é Chafurdo das cópias: histórias da Moda com bandidos e mocinhas, nobres e plebeus. 0 nome do autor: Humberto Piro. Aliás, um nome falso. Sublinho o falso, vocês mais adiante entenderão o porquê. 0 nome verdadeiro dele é Humberto Pinheiro Lopes. A defesa ocorreu em 2012, na Faculdade de Artes Visuais, na Universidade Federal de Goiás.

Eu li a dissertação de Humberto Piro como uma espécie de sofisticado cordel. E as narrativas de cordel são mesmo esmeradas invencionices, e o melhor de tudo é que são tremendamente musicais. Destacam-se as sonoridades das palavras, por isso é gostoso lê-las em voz alta. E palavra puxa palavra, ideia puxa ideia, e de forma descontínua e rigorosa um tema vai se tramando, e vamos sendo enlaçados por aquele saber em que a oralidade prevalece sobre a rigidez do código escrito, aplicando-lhe golpes de torção para amansá-la.

Humberto é cearense de Fortaleza, migrou para Goiânia e se alojou no Programa de Pós-Graduação em Cultura Visual da Universidade Federal de Goiás. Mas, percebam, se eu lhes disse antes que leio a dissertação de Humberto como se lesse um folheto de cordel, vocês já devem estar imaginando que criei uma inevitável equação, de um tipo bem corriqueiro: ele é nordestino, Nordeste tem repente e cordel, evocação das raízes, e essa coisa toda. Até tem isso, mas de viés. Prefiro começar suprimindo as tais raízes. Se Humberto as têm, são de uma espécie aérea. 0 moço é nordestino, tem essa aptidão para uma fala melódica cheia de expressões saborosas, e embora dono de um coração chafurdado, palavras dele, é um sujeito bem cosmopolita, moço em trânsito por aí. A lógica de funcionamento de Humberto é da adição: e e e... além de quebradiça, das quebradas, dos volteios, e se afirma pela contrariedade dos modos de se pensar retilineamente.

Pois bem, rebobinando a fita e apresentando um pouco mais nosso protagonista, um dia me chega no Colóquio de Moda, no GT Moda e Territórios de Existência: processos de criação e subjetivação, coordenado por mim e Cristiane 
Mesquita, parceira de afetos e projetos, um moço muito singular. Ele trazia consigo um jeito cheio de bossa de pesquisar moda. Levou seus Chafurdos, sua pesquisa debaixo do braço, ainda em processo, embora já desse sinais de vigoroso desdobramento chafurdal. Nós duas nos entreolhamos e, numa conversa muda, saudamos aquele acontecimento. Aspiramos isso para o nosso GT: vozes que expandam os estudos da moda, que a complexifique, que lhe dê um chacoalhão estereofônico, multiplicando-Ihe perspectivas.

Originalmente uma Dissertação de Mestrado, Chafurdo das cópias, agora um livro, no prelo da editora da Universidade Federal de Goiás, renova os modos de se pensar-escrever-pesquisar moda. Sua escrita é movida a inquietações e perplexidades diante de sua prática de designer de moda. Demasiado atento ao que se passa à sua volta, Humberto percebe de cara um descompasso entre essas práticas de moda que vivenciou na Universidade, que enfatizam a criação, e o universo das confecções, voltado para o consumo popular, com seus produtos de moda girando em torno da produção das cópias de artigos originais, com pedigree. Que perspectiva adotar diante do que lhe azucrinava?

Armou-se de um finíssimo elenco de interlocutores, refiro-me aos autores-caixas de ferramenta que soube escutar, para com eles escrever sua dissertação. Dentre eles, destacaria a contribuição contundente de Ludmila Brandão, que vem pesquisando de modo inovador as práticas subalternas de consumo das cópias, recusando-se a julgá-las e condená-las de antemão, propondo outras perspectivas mais produtivas, apostando, por exemplo, na potência de subversão que as cópias desencadeiam, embaralhando códigos de distinção e prestígio, abalando ideais arraigados de originalidade e bom gosto estético.

Vejo em Humberto um cartógrafo de primeira, e ainda que não caiba aqui desenvolver o conceito de cartografia, e toda sua implicação metodológica, eu gostaria de, ao menos, registrar alguns dos seus principais fundamentos: o pesquisador-cartógrafo está absolutamente imerso na pesquisa. Ele não deseja e nem quer ocupar um lugar asséptico de neutralidade científica. Ele não sabe com exatidão para onde a pesquisa o conduz. E isso não quer dizer que lhe falte uma direção. Ele toma notas, traça algumas coordenadas, mas elas não se dão em linha reta, mas por vieses, por ziguezagues. E Humberto tem absoluta consciência disso. Receptivo aos fluxos do Fora, falo de um campo social, político, estético, que vibra, e com o qual se permite contaminar, ele vai ao mesmo tempo mergulhando no plano da experiência e se pondo em movimento, desmanchando alguns territórios de certeza, abraçando outras perspectivas, outros modos de decifrar os signos que o forçam a pensar e a aventurar-se a escrever, buscando dar visibilidade às suas interrogações.

Quero saudá-lo sobretudo por conseguir um raro resultado, essa fina conjunção entre saber e sabor, inestimável legado barthesiano, em tempos academicamente insossos. Desculpem-me o desabafo e, decerto, o tom exagerado. Mas não raro a gente se depara hoje com uma produção proliferante de "papers", cada vez mais funcionais, quase arremedos de planilhas Excel, em que o desejo do pesquisador jamais comparece. Cumpre-se então um ritual desenxabido em que pensamento e vida são mantidos apartados. Não se contaminam de jeito nenhum. Para ilustrar melhor isso, tomo carona numa ideia de Michel Foucault e assumo o risco de distorcê-la: mas não escrevemos um artigo, uma dissertação ou uma tese, para a gente se tornar outro, diferente daquele que éramos no início?

Tudo que eu disser é pouco diante do engenho e inteligência sensivel que percorrem as páginas dessa dissertação. Humberto é um pesquisador à espreita do que se passa ao seu redor e não evita tomar caminhos ziguezagueantes para interrogar os espaços pessoais e teóricos em que pisa. Desconfia saudavelmente das ideias prontas, e toma como ponto de partida suas próprias indagações e perplexidades no campo da moda, desdobrando-as em aventura de conhecer mais de perto o que significa mesmo cópia, original, imitações, roubo, plágio, pirataria. É uma peleja o que o autor trava consigo mesmo, não exatamente para esclarecer tudo, inexiste essa pretensão. Existe sim uma inequívoca compreensão de que mal uma azucrinação termina, outra já bate à nossa porta, e lá vamos nós chafurdar em outros territórios, na tentativa de desconstruir qualquer enunciado categórico que cruze nosso caminho. De chafurdagem, Humberto entende à beça. 